\title{
REVIEW
}

\section{Thinking about children's attachments}

\section{A Rees}

Arch Dis Child 2005;90:1058-1065. doi: 10.1136/adc.2004.068650

Disordered parental attachment can commit children to lives characterised by relationship difficulties, behaviour problems, educational failure, and poor self-esteem. It is a major root of trans-generational neglect and abuse and frequently underlies mental health problems, drug and alcohol addiction, homelessness, and crime. Early childhood setting of hypothalamus-pituitary-adrenal axis function appears to contribute to these costly difficulties. More broadly, the concept of attachment can contribute to defining and managing the psychosocial dimension of routine paediatric care. The current under-representation of attachment in paediatric education, practice, and research needs to be rectified.

Correspondence to: $\operatorname{Dr} C A$ Rees, Tyndalls Park Children's Centre, 31 Tyndalls Park Road, Bristol BS8 1PH, UK; drcarees@doctors.org.uk

Accepted 8 June 2005
A ttachment is, essentially, the enduring emotional closeness which binds families, enabling children to be brought to independence and to parent in their turn. It is the template for the emotional rapport which is the stuff of all relationships, and thus of the functioning of society. At an individual level it is to do with the experience that "safety" physical and emotional-is achievable through relationships.

While everyone needs attachment, for children it is the means to independence. The long duration of human childhood testifies to its importance and reflects the complexity of tasks involved. Attachment gives children the trust and safety necessary to explore, learn, and relate, and the physical wellbeing, motivation, tools, and opportunity to do so. Implicit in "safety" is the ability not only to recognise risk but also to adjust to it, both automatically and in a more considered way. Attachment is the foundation for doing so. Implicit in "trust" is the notion that relationships are mutually beneficial. Early attachment has lifelong implications for personal, social, and professional relationships, stress regulation, and physical and psychological health. Without it, "protection of children, prevention of illness and disease in children and safeguarding their optimal development ${ }^{\prime 1}$ is a vain hope.

Bowlby's conceptual description of attachment $^{2}$ is supported by a wealth of observation and, increasingly, by neurobiological evidence. Ainsworth et al categorised toddlers' varying responses to separation from and reunion with their parents. ${ }^{3}$ The observed patterns of relationships ("attachment styles") are now recognised to originate in infancy and to track throughout the lifespan, albeit modified by later experience-influencing behaviour, health, career choice, and personal relationships (box 1). While "secure" attachment style may give the most comfortable personal path through life, societies benefit from attributes common among those with "insecure" attachment styles, the implied pathology having qualified justification. For example, those whose "insecurity" is manifest in anxiety to be needed or noticed can excel as "carers", actors, or socialites, while those who seem emotionally self-sufficient, although tending to be socially inexpert often have particular talent with the inanimate or conceptual-computers or mathematics, for example. Attachment style forms a continuum on which pathology is imprecisely defined. It is a problem if it is a problem. It may colour, mould, or define children's experiences in illness and health. Resilience varies for many reasons, both individual and social, and what is "good enough attachment" for one person may not be for another.

Much of the harm of abuse is that of disturbed attachment. Bruises heal quickly but the emotional relationships surrounding them can have implications for generations to come. The bruise may in fact, ironically, be the saving grace which allows professionals to respond since it is more readily defined. The powerlessness which many feel when witnessing emotional neglect unaccompanied by physical or sexual abuse can be helped by defining it in terms of the nature and implications of the inadequate attachment it represents. The difficulty is partly that this is rarely black and white-neglect and abuse can sit alongside aspects of important attachment. The nature of family attachments is thus a key consideration in weighing up risks and benefits of foster care, and in safe interpretation of parents' and children's responses to removal and contact. When attempting rehabilitation, recognition of the implications for family relationships of the child's moves into and within foster care determines the preparation and support needed. Similarly, when adoption is required, children's preconceptions of relationships are important considerations which profoundly colour the experience for all concerned.

Inadequate attachment is highly costly to individuals and to society. It frequently underlies drug and alcohol addiction, homelessness, criminality, and mental health problems ${ }^{5}$ and is a core strand in trans-generational parenting difficulty. ${ }^{6}$ Protection of attachment concerns all paediatricians, through recognising risks, actively promoting infant attachment, and identifying signs of attachment difficulty and its consequences. 
Box 1: Attachment styles; commonly used terminology and characteristics

Secure attachment: Value relationships but independently confident of self-worth

\section{Insecure attachment:}

- Avoidant: Appear emotionally independent. Skills tend to lie with the inanimate rather than the personal/social

- Anxious: Depend on the attention/approval of others for self-worth

- Ambivalent: Depend on relationships but also seem wary of their safety

- Disorganised: Neither effectively self-sufficient nor able to use relationships

Note: A confusing array of terminology is currently in use, affecting clinical and research application. ${ }^{4}$ These categories coalesce: description can be more helpful than labelling. "Insecure" attachment style is not necessarily pathological.

Attachment colours all areas of paediatric practice. The question is not whether it is relevant, but how and to what extent. Insecurity of attachment may be relevant to symptom causation or perpetuation-excessive crying in infancy, sleep problems, conduct disorder, attention deficit hyperactivity disorder (ADHD), soiling and wetting, failure to thrive and obesity, accidents, small head circumference, and developmental delay among many. With every symptom children behave and parents respond in ways influenced by their respective attachment patterns For example, anxious attachment predisposes to use of symptoms, however trivial, for attention. Parents' and children's attachment styles may be relevant to mode of symptom presentation, the course of consultations, treatment compliance, clinic attendance, progress of recovery, and optimal management. The course of chronic illness, and resilience in the face of it, may both influence and be influenced by family attachments, particularly when illness straddles attachment related developmental stages. Care of adolescents requires particular awareness of the importance of attachment for safe separation, and of the complex dynamics around this into which professionals can readily unhelpfully be drawn. Adolescent attachment is characterised by paradox and ambiguity-the need, for example, for dependence to allow independence and for containment to allow empowerment. Recognition of this is necessary for protection of key relationships and for safe negotiation of consent.

Experienced paediatricians who routinely consider the "whole family" may reasonably wonder what greater awareness of attachment might add. It is really a matter of perspective. Seeing through "attachment tinted lenses" can make it easier to understand, analyse, and respond to many notoriously challenging aspects of practice. It contributes conceptually to defining and managing the psychosocial dimension of paediatric care. Recognising this as ubiquitously relevant enables the bigger picture of family and social relationships to be considered constructively, without judgement or implied criticism. It follows that this must be integral to paediatric practice and not territory only for Child and Adolescent Mental Health Service (CAMHS) professionals

Table 1 Attributes acquired through normal parental attachment and affected by disordered attachment

\begin{tabular}{|c|c|}
\hline \multicolumn{2}{|l|}{ Attribute } \\
\hline $\begin{array}{l}\text { Understanding of the "inner world" Recognition and correct } \\
\text { attribution of body signals - pain, hunger, satiety, } \\
\text { toilet needs, temperature } \\
\text { Understanding and expression of emotions appropriate } \\
\text { to circumstances; language for feelings } \\
\text { Rationalising, remembering, planning, problem solving }\end{array}$ & $\begin{array}{l}\text { P, age 3, was adopted because of neglect. He did not react to minor injuries. He showed no } \\
\text { awareness of the need for the toilet. He ate without limit if allowed, to the point of vomiting. } \\
\mathrm{K} \text {, age 4, was neglected before adoption. In her adoptive home, she showed no sense of fun or } \\
\text { enjoyment, did not cry and showed little temper. She seemed unaware of the feelings of others. }\end{array}$ \\
\hline $\begin{array}{l}\text { Stress regulation Parental attunement regulating the } \\
\text { child's stress } \\
\text { Stress regulatory system permanently set } \\
\text { Routine, predictability, cognition, trust-reducing anxiety }\end{array}$ & $\begin{array}{l}\text { M, age 17, was adopted age } 18 \text { months after initial neglect. Although well attached and socially } \\
\text { integrated, his temper has always been a problem, despite CAMHS help. It "flares } 0 \text { to } 100 \text { with } \\
\text { no in between" and he feels out of control. He "turns grey" and his "eyes change". }\end{array}$ \\
\hline $\begin{array}{l}\text { Understanding of relationships } \\
\text { Benefits of relationships } \\
\text { Closeness } \\
\text { Cooperation } \\
\text { Communication } \\
\text { Strategies to achieve attention } \\
\text { Verbal and non-verbal communication; nuance, } \\
\text { humour, gesture, facial expression, touch, behaviour } \\
\text { Experience of mood and emotion as communicable } \\
\text { Empathy } \\
\text { Social rules, authority, hierarchy, types of relationship }\end{array}$ & $\begin{array}{l}\text { J, age } 4 \text {, was neglected. At } 2 \text { y } 9 \mathrm{mth} \text {, after } 9 \text { mth in care, he appeared autistic with no speech or } \\
\text { eye contact, and ritualistic play. These problems settled. } \\
\text { P, age } 5 \text {, learned to gain closeness by sexually provocative behaviour, and } \mathbf{H} \text {, age } 6 \text {, by } \\
\text { excessive compliance. } \\
\text { A, age } 11 \text {, was neglected. Her early speech development was delayed. Since adoption at age } 5 \\
\text { her speech remains unsophisticated, missing nuance and humour. She is affectionate and } \\
\text { caring, but misjudges social situations. } \\
\text { L, age } 7 \text {, learned to take control in the face of inadequate parenting. While very engaging, her } \\
\text { adopters experience her as sly and manipulative, and unfamiliar with the concept of parental } \\
\text { authority. Discipline is problematic. She is similarly controlling of peers and friendships are } \\
\text { short-lived. }\end{array}$ \\
\hline $\begin{array}{l}\text { Understanding of the outside world } \\
\text { Cause and effect } \\
\text { Socially acceptable norms of routine and behaviour } \\
\text { Awareness of danger }\end{array}$ & $\begin{array}{l}\text { T, age 4, was neglected and exposed to violence at home. He shows no awareness of danger } \\
\text { and will climb to or jump from excessive heights if unsupervised, such that he needs to be } \\
\text { watched constantly. In shops he is liable to run off without turning to look for his foster mother. }\end{array}$ \\
\hline $\begin{array}{l}\text { Ability to explore the world } \\
\text { Inquisitiveness } \\
\text { Motivation } \\
\text { Cognitive and motor skills for exploration } \\
\text { Opportunity } \\
\text { Safety to explore } \\
\text { Routine and safety allowing concentration }\end{array}$ & $\begin{array}{l}\text { O, age 3, previously neglected, shows no spontaneous curiosity and, if allowed, "just sits". She } \\
\text { shows no imaginative play. She walks "through", not round obstacles. Her adoptive parents } \\
\text { have had to teach her to want to play as well as how to do so. } \\
\text { J, age } 10 \text {, experienced domestic violence until age } 2 \text {. He formed significant but insecure } \\
\text { attachment to his adoptive parents. He has prominent features of ADHD. Disruptive behaviour } \\
\text { and tempers have led to school exclusion. }\end{array}$ \\
\hline
\end{tabular}


Box 2: Analysis of problems at school age relating to attachment disorder

\section{Behaviour problems}

- Strategies adaptive to neglect/abuse

- Controlling adults-opposition, manipulation, "slyness", lying

- Hypervigilance-poor concentration, "over-reading" of anger cues, etc

- Attention seeking

- Confused expectations

- Lack of experience of discipline

- Multiple sets of rules due to moves

- Ignorance of social rules

- Communication difficulties

- Inability to "read" behaviour, nuance, emotional content of language, humour, etc

- Unsophisticated expressive language

- Emotional awareness

- Limited emotional repertoire

- Lack of empathy

- Stress regulation difficulty

- Temper control problems

- Difficulty with trust and authority

- Cognitive difficulty

- Cause and effect, planning, reflection

- Fear of failure

- Difficulty handling change in routine

- Lack of concept of safety

- "Flashbacks"

- ADHD symptoms

- Anxiety; depression

\section{Peer relationship problems}

- Communication difficulties (as above)

- Lack of empathy

- Vulnerability to failure and rejection

- Bullying or being bullied

- Temper control problems

- Needing to control others

- Poor personal hygiene

- Social consequences of behaviour problems

- ADHD symptoms

- Anxiety; depression

\section{DEVELOPMENT OF ATTACHMENT}

The key to attachment is attunement. Put simply, the baby's cry elicits a calming parental response, reinforcing a learnt pattern for both. ${ }^{7}$ In fact this is a highly sophisticated duet, involving tone, pitch and rhythm of voice, posture, facial expression, movement, and touch. ${ }^{8}$ This moulds development of the experience dependent brain-particularly the occipitofrontal cortex-in a process requiring both the baby's ability to elicit a response and the parent's to respond. ${ }^{9}$

Stress regulation-a prerequisite for exploration, learning, and effective relationships-is a key aspect of this. Involuntary aspects, mediated by the hypothalamus-pituitary-adrenal (HPA) axis, are set in infancy-and probably antenatally-at a level adaptive to environment. "Higher"

\section{Poor self-esteem}

- Relating to abuse/neglect

- Internalised negative self-image

- Feelings of responsibility for abuse

- Poor personal hygiene

- Shame

- Relating to separation from birth family

- Concerns re identity

- Confusion re life history

- Feeling "different"

- Guilt re family break-up

- Sense of rejection by birth family

- Lack of opportunity to succeed

- Educationally

- Socially

- Frequent reprimand

- ADHD symptoms

- Anxiety; depression

\section{Educational difficulty}

- Gaps in foundations for learning

- Specific learning difficulties

- Relating to causes of poor attachment

- Intrauterine drugs/alcohol

- Familial learning difficulty

- Opportunity

- Poor attendance

- Changes of school due to moves

- Exclusion

- Lack of confidence to try

- Difficulty in accepting failure

- Difficulty in accepting authority

- Difficulty sharing attention

- Peer relationship difficulties

- ADHD symptoms

- Anxiety; depression

\section{Mental health problems}

- Depression

- Anxiety

- Post-traumatic stress disorder

- Obsessional compulsive disorder

aspects, located in the right hemisphere, ${ }^{9}$ build on and regulate, but do not replace involuntary mechanisms. Hence, while neuronal plasticity, developing cognition, and experience modulate stress responses, they do so around a baseline reflecting initial relationships. This principle can be extrapolated to other aspects of development.

Attuned parental responses impart meaning to the "inner world" of body signals (for example, hunger, satiety, full bladder), thought (for example, recall, anticipation, problem solving), and emotions. The child learns that his emotions and behaviour influence those of others, who recognise his needs. Herein are the foundations for trust and empathy, understanding relationships and the subtleties of communication, non-verbal and verbal. Expectations ("internal working models") are established for subsequent relationships, close and otherwise. ${ }^{10}$ Close relationships become distinguishable from others (table 1). 
Increasing distancing from the mother is allowed in progressing from maintaining closeness initially through touch, to visually in the toddler years, then, increasingly, through language-including, specifically language for feelings. Trust allows security during physical separation and the emotional "separation" of discipline-the foundation for accepting authority and, through unconditional acceptance, for self-esteem. The "secure base" of attachment, remains, paradoxically, the cornerstone of growing independence throughout adolescence.

\section{CHILDHOOD ORIGINS OF ATTACHMENT STYLES}

Early attachment experiences, coloured by innate characteristics and experience shape approaches to all relationships. Consistently sensitive and responsive parenting teaches that closeness is valuable and that moderate distress elicits a response-the foundation of secure attachment. However, attunement presupposes "availability", whether physical or emotional. For many parents this is not the case, whether through drug or alcohol abuse, mental health problems, or the practical demands of parenting several children. Many cannot attune since nobody attuned to them in childhood. Intermittent responsiveness (for example, through drug addiction) engenders anxiety, teaching that closeness is valuable but unreliable. Strategies are learnt to achieve itranging from constant smiling or excessive compliance to disruptive behaviour, smearing, wetting, or sexually provocative behaviour. Parents who are sometimes responsive but sometimes antagonistic (for example, because of temper control problems) teach that closeness is worth striving for, but often frightening, creating ambivalence-the child who, confusingly, seeks but is not calmed by closeness, uses closeness inconsistently or resists sustaining it. Consistent unresponsiveness (for example, through parental learning difficulties) teaches children not to seek closeness. Abuse by parents, or loss of important relationships, may likewise encourage avoidance of closeness, sometimes mimicking autism. When parents are a constant source of fear children may fail to learn strategies either for effective self-sufficiency or for using relationships, showing "disorganised" attachment behaviour.

As in any relationship, parent-child attachment is a two way process, dependent on what each contributes, opportunities for closeness, and the effects of, and on, other relationships. Apparent avoidance of closeness may reflect innate difficulty in responding, acquired intolerance of closeness (as with the irritability of drug withdrawal or neurological problems), lack of parental "availability", or taught self-sufficiency. Anxious and ambivalent relationships may reflect innately anxious personality, cognitive difficulty, erratic parental availability, difficult subsequent relationships, or instilled anxiety.

The cause of parents' difficulties does not predict children's attachment patterns precisely. Drug addiction, for example, often allows intermittently attentive parenting, creating anxious attachment, though associated violence may produce ambivalence or avoidance of closeness. Abuse can cause avoidance of closeness, anxiety, or total disorganisation. Parental behaviour and resulting attachment patterns are changeable and distinctions blurred. Circumstances and "availability" change. One responsive parent may compensate for the other's shortcomings and any close relationship may protect. Patterns are neither entirely mutually exclusive nor entirely fixed-though tendencies persist.

Table 2 A framework for focusing on attachment in child protection decisions

\begin{tabular}{|c|c|}
\hline Assessment & Framework \\
\hline $\begin{array}{l}\text { Child protection assessment } \\
\text { "How can emotional safety } \\
\text { best be protected?" }\end{array}$ & $\begin{array}{l}\text { What are the parents' childhood experiences likely to mean for parenting? } \\
\text { What are the current risk factors for attachment? (parents, child, social, etc) } \\
\text { What does observed attachment behaviour suggest about home experiences? } \\
\text { With whom/what are the child's important relationships? } \\
\text { What factors are likely to have contributed to abuse? Which are remediable? } \\
\text { What is the "attachment context" of abuse - and what may this mean for the child's } \\
\text { response to removal? (e.g. "favoured child", scapegoat, rejected) } \\
\text { What are the risks and benefits of foster care? } \\
\text { Do the benefits of unprepared emergency placement justify the risks? } \\
\text { How can the risks of emergency placement be reduced? } \\
\text { Is it possible to engage the birth family in supporting a move? } \\
\text { Is there another familiar adult who could support a move? } \\
\text { Does he have a comforter/toy/pet which could go with him? } \\
\text { How can family relationships be protected? (e.g. independent parental support) }\end{array}$ \\
\hline $\begin{array}{l}\text { Assessing long term placement needs } \\
\text { "Where is adequate long term } \\
\text { attachment most likely to be } \\
\text { achieved?" }\end{array}$ & $\begin{array}{l}\text { Is it likely that his attachment needs can be met within the family home? } \\
\text { What factors are contributing to attachment difficulties? (factors relating to parents, } \\
\text { child, opportunity, support, understanding of attachment, etc) } \\
\text { Which of these may be changed? Within what timescale? } \\
\text { Is there a reasonable likelihood of adequate overall change sufficiently soon, bearing } \\
\text { in mind the natural history of attachment problems? } \\
\text { Is it likely that adequate attachment can be established away from home? } \\
\text { What measures would be needed to make this possible? } \\
\text { Which relationships will it be in the child's best interest to protect? How? } \\
\text { What does the nature of his sibling relationships mean for how long term attachment may } \\
\text { best be achieved? Do the advantages of placing the siblings together outweigh the risks or vice versa? } \\
\text { What are the implications of his attachment pattern for choice of family? }\end{array}$ \\
\hline $\begin{array}{l}\text { Planning moves to foster care, } \\
\text { adoption, or back home } \\
\text { "How can the likelihood of achieving } \\
\text { adequate attachment be maximised?" }\end{array}$ & $\begin{array}{l}\text { How (judging from past experiences) is the child likely to view a move? } \\
\text { What are his preconceptions of adults/closeness? } \\
\text { How (judging from past patterns) is he likely to behave? } \\
\text { What are the implications for: } \\
\text { How adopters will feel } \\
\text { Family dynamics } \\
\text { Preparation and support needed for the child and family } \\
\text { Specialist/CAMHS services needed } \\
\text { How can the birth family/foster carers be helped to support the move? }\end{array}$ \\
\hline
\end{tabular}




\section{RISK FACTORS}

Bearing in mind that attachment is a two way process, risk may lie in attributes of the child or parents, in opportunity for closeness, and in family and social relationships. Disability, traumatic delivery, post-natal depression, neonatal intensive care, circumstances of conception, altered family dynamics, and social attitudes can contribute.

However, attachment difficulty sufficient to lead to adoption almost invariably originates with the parents. Most lacked a parenting role model, were in care, or abused. Many have learning difficulties, mental illness, temper control problems, or drug or alcohol addiction-often several of these (Selwyn et al, 2003; unpublished). Routine enquiry in antenatal clinics about parents' early attachment experiences would offer scope for education and focused intervention. Such information should be integral to child protection assessment.

\section{CONSEQUENCES OF ATTACHMENT PROBLEMS}

Disturbed attachment can affect all that should come of dependency, but particularly prominent aspects are, broadly, social communication, emotional awareness, and stress regulation. At school age these translate to interrelating problems with peer relationships, self-esteem, education, and discipline (box 2). Vicious circles and cascades of escalating difficulty follow, risking failure to sustain adult relationships, unemployment, homelessness, criminality, self-injurious behaviour, and parenting problems. Adolescence brings particular vulnerability.

Salivary cortisol marks an important thread throughout. The emerging picture suggests that some, in response to early traumatising relationships may switch off their stress responses-effectively withdrawing emotionally, becoming "fearless". Others' stress responses become exaggerated, carrying risk of anxiety, depression, and post-traumatic stress disorder. ${ }^{11-13}$ The relevance of cortisol to attachment suggests research which might help to refine the non-accidental injury evidence base, in view of the relation of cortisol to ease of bruising, bone density, and rate of healing. Both suppressed and exaggerated patterns of stress responses have implications for behaviour regulation, compliance, and discipline. ${ }^{14}{ }^{15}$ Associated changes in bowel flora and immunological and cardiovascular function need further exploration. ${ }^{16-19}$ The neurobiology of attachment illustrates one mechanism for the straddling of physical and psychological symptomatology, mediated by autonomic function and cortisol, with potential relevance to wider aspects of paediatric practice.

Depression frequently follows disturbed early attachment although its manifestations may be confusing-inviting failure and rejection, for example. A prominent need for order following early chaos can fuel obsessionality. With associated fear of closeness, literal language, limited empathy, and difficulty reading social cues this may mimic autism. Mistrust of authority and learnt self-protective strategies for maintaining control contribute to oppositional problems.

ADHD is complexly related to disturbed attachment, as both cause and effect. Familial ADHD is likely to be overrepresented among those with attachment difficulty. Impulsive parents struggle to parent impulsive childrenand ADHD may underlie the drug, alcohol, and temper problems which precipitate neglect. Antenatal risk factors for ADHD—drugs, alcohol, smoking, and maternal anxiety-are common among those with attachment difficulty. Hypervigilance in response to aggressive parenting and chaos precludes concentration. Hyperactivity may serve to avert closeness, or to attract attention. Hyperactivity and inattention, in turn, impair both physical and emotional closeness. Such behaviours escalate following moves, risking placement breakdown. ${ }^{20}$ New parents struggle to cope without a safety net of mutual attachment. A trajectory of multiple moves may follow.

\section{ATTACHMENT ISSUES IN DECISION MAKING IN CHILD PROTECTION AND SUBSTITUTE CARE}

Attachment is central to evaluating risks and benefits of child protection decisions (table 2). Physical protection may be

\section{Box 3: Observing attachment in a general} paediatric setting

0 to 6 months

- Does he make eye contact with, "follow", direct gaze towards the parent?

- Does he smile, vocalise, imitate socially?

- Does he indicate discomfort?

- Does he calm with parental comfort/closeness?

- Does the parent attune to his behaviour (by eye contact, touch, facial expression, tone of voice, action, etc)?

6 months to 1 year

- As for 0 to 6 months

- Does he show stranger anxiety?

1 to 3 years

- As for 6 months to 1 year

- Does he make eye contact?

- Does he relate preferentially to parents rather than unfamiliar adults?

- Does he refer back to his parents in play?

- Does he respond appropriately to closeness?

- Does he go to his parents if hurt?

- Does he look to his parents if a stranger comes in, or before going off with a nurse?

- Does he seek affection from strangers?

- Does he seek attention appropriately, too little or excessively?

- How does he respond if his mother's attention is on his sibling?

- Does he move away and play independently?

- Does he show feelings appropriate to circumstances?

- Does his play suggest adequate attachment? Is he inquisitive? Is he caring to dolls?

- Are his parents attuned to his needs and emotions (verbally, non-verbally, in actions)?

\section{Over 3 years}

- As for 1 to 3 years

- Does he intrude excessively on professional conversation with his parents?

- Does he focus attention in play? Does he explore toys?

- Does he show imaginative play involving feelings?

- Does he respond to authority? Who is controlling whom?

\section{Adolescence}

- Does he function effectively independently?

- Is antagonism selectively directed towards parents rather than professionals?

- Does he use family support at times of illness, injury, etc?

- Does he show empathy? 
achievable only at the cost of significant emotional harm. Decisions about the nature, purpose and timing of interventions should focus on the priority of securing attachment and the natural history of attachment difficulties.

The key practical question is "when is it too late?" Neurobiological evidence explains the observed importance of initial attachment in protecting against subsequent inadequacy-adequate foundations may allow some room for manoeuvre. ${ }^{91}$ The longer children are deprived of adequate attachment, the greater the risk of inability to achieve it. ${ }^{22}$ The likelihood of good recovery, even with optimal opportunity, progressively falls, though neuronal plasticity offers some resilience. Cortical atrophy becomes increasingly irreversible, with little demonstrable recovery a year later if children are removed from neglect after age 4 years. ${ }^{23}$ Disordered attachment in infancy permanently affects HPA axis function. ${ }^{9}$

Secondary difficulties escalate with age, while the likelihood of identifying an adoptive placement diminishes. The outlook is bleak for those who by adolescence fail to achieve attachment sufficient for safe separation. The drive for independence makes integration into an adoptive home difficult in the unlikely event of finding one. While it is tempting to persevere when there is any chance of family care, the risks of passage of time mean that the probability, not the possibility of change needs to be considered. Age, and the timescale of interventions are key considerations. The practical need is to move forward regardless of cause, analysing what can be changed, how soon, and the cost of delay.

Decisions to accommodate must balance risk with the likelihood of success. This means recognising attachments to parents and others-teachers, siblings, and pets. Emergency placements are particularly hazardous since attachments cannot be assessed, risks identified, or children and families prepared. Difficulty managing the behaviour of distressed children risks placement breakdown, leading some to a trajectory of multiple moves and escalating damage. Balancing emotional harm against physical safety may entail accepting some risk. Hope of ultimate reunification determines the professional responsibility to minimise damage to key relationships through removal.

Attempted rehabilitation should be supported by awareness that both child and family are changed by separation. Preparation and support are as important as in moves to adoption. In both situations a broad focus on the child, parents, environment, family dynamics, and support networks gives the best chance of success.

The appropriateness of adoption, choice of family, and preparation and support needed for adoptive parents and children depend on the nature of birth family relationships. Children are to some extent attached even to the most abusive of parents, if only through familiarity. Loyalty to parents, sexual abuse in the context of "the favoured child", perceived responsibility for family break-up, and experience of partially attentive parenting may all cause rejection of alternatives. It is rarely more difficult to engage parents, nor more important, than when children are removed from their care. Their support is often the key to allowing the child to move on. Acknowledgement of the origins of their own difficulties may enable them to feel less judged, tempering antagonism for some. Counselling independent of social services may enable some to support their child.

\section{ASSESSING ATTACHMENT}

In a busy clinic observation may raise concern about adequacy of attachment and its relevance to presenting problems (box 3). Frequently, though, the more relevant question is not "Is there an attachment problem?" but "What

Table 3 Asking about attachment

\begin{tabular}{|c|c|}
\hline Context & Time in adoptive placement; circumstances of removal from home, etc \\
\hline Parental risk factors & $\begin{array}{l}\text { Parental childhood attachment; drugs, alcohol; mental health problems; learning difficulty; anger management } \\
\text { problems }\end{array}$ \\
\hline Experiences in the family home & $\begin{array}{l}\text { Closeness; multiple carers; violence; abuse; parental predictability; physical care; routines (meals, day-night, etc); } \\
\text { times of better care; other important relationships; role in family ("parental" role, scapegoating, "favoured child", } \\
\text { rejection); nature of sibling relationships }\end{array}$ \\
\hline Moves & Number of moves; preparation for moves; response to moving \\
\hline Use of closeness & $\begin{array}{l}\text { Does he enjoy physical affection? Does he seek closeness? Does he do so appropriately (not sexualised)? Having } \\
\text { sought closeness, can he use it? Does he accept offered comfort? To whom, if anyone, does he go if hurt? }\end{array}$ \\
\hline Stranger awareness & $\begin{array}{l}\text { Is he wary of strangers? Would he seek affection of strangers? Would he go off with a stranger? Was he } \\
\text { affectionate immediately on moving in? }\end{array}$ \\
\hline Need for attention & $\begin{array}{l}\text { Does he seek attention? Can he share attention? Can the parent chat with a friend or make a phone call? What } \\
\text { does he do to gain attention? }\end{array}$ \\
\hline Stress regulation & Does he startle easily, show normal fear, mood swings, excessive anxiety? \\
\hline Emotional awareness & $\begin{array}{l}\text { Does he express a normal range of emotions? } \\
\text { Does he show empathy? Is he kind to pets, dolls, etc? } \\
\text { Does he show temper or aggression? When? How often? Is it excessive? }\end{array}$ \\
\hline Communication & $\begin{array}{l}\text { Does he understand nuance, humour, emotional content of language? } \\
\text { Does he use words for feelings? Does he understand non-literal meaning? }\end{array}$ \\
\hline Body signals & $\begin{array}{l}\text { Does he read non-verbal communication well? Does he "read" situations? } \\
\text { Does he respond appropriately to pain, cold, hunger? } \\
\text { Does he know when he has eaten enough? Does he take others' food, eat rubbish, eat until he vomits? } \\
\text { Does he know when he needs the toilet? }\end{array}$ \\
\hline Play pattern & $\begin{array}{l}\text { How does he use toys? Is he inquisitive? Is he imaginative? Does he get into roles-including feelings? Is he } \\
\text { affectionate with soft toys, dolls, etc? }\end{array}$ \\
\hline Discipline & $\begin{array}{l}\text { Does he accept authority? Does he allow others to take control? } \\
\text { Does he want to please? Excessively? Does he respond to praise? How does he react to discipline? Does he show } \\
\text { conscience or remorse? }\end{array}$ \\
\hline $\begin{array}{l}\text { Behaviour in public places } \\
\text { Safety } \\
\text { Peer relationships }\end{array}$ & $\begin{array}{l}\text { What is he like out in public? Does he stay with the parent? If he runs off, does he look for or return to the parent? } \\
\text { Does he have a concept of safety? Does he let this regulate his behaviour? } \\
\text { How does he get on with other children? Can he cooperate? Can he share, or lose? Does he try to control others? } \\
\text { Does he bully? Is he bullied? Does he understand social "rules"? }\end{array}$ \\
\hline Concentration & Are there ADHD type features? \\
\hline Change & How does he react to change in routine, unexpected events etc? \\
\hline Self-esteem & Can he cope with teasing? Does he accept praise? Does he show pride? \\
\hline
\end{tabular}


does the observed pattern of family attachments suggest about how the child and family may be helped most effectively?".

The central question is "How does the child use adults?". One considers whether he seeks closeness and attention appropriately (suggesting secure attachment), too little (suggesting avoidance), or too much (suggesting anxious attachment); whether he seeks but is not calmed by closeness or seeks it inconsistently (suggesting ambivalence), or whether his interpersonal behaviour appears chaotic and ineffective (suggesting disorganised attachment). Attachment style is frequently transmitted from parent to child, and parental interactions can yield helpful insight into children's attachments. Detailed assessment requires analysis of information gathered from community based services (table 3). Description is more important than labelling, which needs a clear purpose.

Context affects interpretation. This is rarely more important than in evaluating options for permanency while children are temporarily "looked after". Overlooking the bigger picture carries risk of misinterpreting children's responses to accommodation or subsequent parental contact. Poor attachment of an accommodated child may not mean inability to attach. Each relationship is unique and ability to attach to one person does not necessarily predict ability to do so to another. Rate, strength, and quality of attachment vary within and between relationships. Initial avoidance of closeness is usually a healthier sign than the converse. A child's attachment to his parents may make him resist alternatives. He may dislike the foster carer. The foster carer may herself have attachment difficulties. ${ }^{24}$ Frozen unresponsiveness on moving to foster care may reflect fear of what is, not of what has gone before. Distress on seeing parents may reflect love, not fear. Relationships are dynamic, so snap-shot views, like photographs of moving objects, are not necessarily representative, and sometimes entirely deceptive. Over-hasty interpretation risks erroneous conclusions.

Unrealistic expectations of attachment frequently cause new adopters unanticipated difficulty. Idealisation founded on years of infertility causes fear and guilt when feelings are

Table 4 Helping attachment

\begin{tabular}{|c|c|}
\hline & Aftachment \\
\hline Helping children to attach to parents & $\begin{array}{l}\text { Closeness } \\
\text { Offering closeness when tired, hurt, ill, and after tantrums, even if not sought } \\
\text { Discouraging closeness with others than immediate family } \\
\text { Opportunities to communicate-shared one-to-one activities } \\
\text { Teaching "language" (verbal and non-verbal) of closeness } \\
\text { Safety (emotional and physical) } \\
\text { Reducing the likelihood of failure } \\
\text { Reducing competition for attention-allowing one-to-one time } \\
\text { Preparation, explanation, routine, etc to reduce anxiety } \\
\text { Avoiding circumstances likely to result in difficult behaviour } \\
\text { Behaviour management: establishing control; clear boundaries; allowing success } \\
\text { Calming strategies-touch, massage, music, etc; anxiety management techniques }\end{array}$ \\
\hline Helping parents to attach to children & $\begin{array}{l}\text { Attunement } \\
\text { Helping parents to "see through the child's eyes" and understand behaviour } \\
\text { Reducing fear/stress/fatigue } \\
\text { Ensuring that expectations for attachment are realistic } \\
\text { Normality of adoptive parents attaching at different rates } \\
\text { Normality of attaching more rapidly to one child than another } \\
\text { Ensuring adequate support in the early stages of placement } \\
\text { Acknowledgement of the difficulty of parenting without attachment } \\
\text { Addressing guilt, fear, self-doubt; identifying signs of progress } \\
\text { Support for post-placement depression } \\
\text { Respite-informal or formal; encouraging self-care }\end{array}$ \\
\hline Secondary consequences/vicious circles & $\begin{array}{l}\text { Understanding body signals - talking re body sensations-hunger, satiety, etc } \\
\text { Understanding emotions } \\
\text { Parental attunement to the child's feelings and mood, not behaviour } \\
\text { Clear/exaggerated verbal and non-verbal responses to the child's feelings- } \\
\text { through touch, facial expression, gesture, tone of voice, etc } \\
\text { Teaching words for feelings; discussion of feelings; use of role play, etc } \\
\text { Teaching reading of body language, behaviour, facial expression, etc } \\
\text { Peer relationships - active support of friendships; teaching cooperation, social skills, etc } \\
\text { Stranger safety-education through discussion, books, play, etc } \\
\text { Self-esteem } \\
\text { Identification and development of strengths; ensuring success; focusing on positives } \\
\text { Life story work to reduce guilt, shame, sense of responsibility for circumstances, etc } \\
\text { Temper control problems - multiprofessional approach addressing causes and symptoms } \\
\text { ADHD-low threshold for treatment, especially if interfering with mutual attachment } \\
\text { Development/education } \\
\text { Detailed assessment } \\
\text { Low threshold for intervention because of risk of vicious circles } \\
\text { Ensuring teachers' understanding of the implications of attachment problems }\end{array}$ \\
\hline Specialised psychological services & $\begin{array}{l}\text { Task definition-purpose, choice of resource, mode of delivery and timing of } \\
\text { services focused on the priority of securing attachment } \\
\text { Service structure-allowing rapidity of response, to address crises } \\
\text { Specific mental health problems } \\
\text { Identification and treatment of depression, obsessional-compulsive disorder, } \\
\text { anxiety, post-traumatic stress disorder, etc } \\
\text { "Attachment therapy"-e.g. for avoidance of or ambivalence to closeness, } \\
\text { difficulties with trust and control, etc, when simple strategies are insufficiently effective }\end{array}$ \\
\hline
\end{tabular}


slow to develop. Parents usually attach at different rates, and to one sibling before another. Challenging behaviour of unsettled children adversely affects closeness. Behaviour once adaptive to inadequate parenting causes confusion and distress. Parenting without attachment is difficult, frightening, and isolating. One cannot know it will happen until it does so.

\section{HELPING ATTACHMENT}

This is a task for all-not only for CAMHS professionals. The importance of early attachment should be reflected in resource allocation, education, antenatal recognition of risk, and urgency of intervention. Key foundations need protection while parenting is assessed-through mother and baby foster placements and improved community resources.

Supporting attachment means recognising the bigger picture-support networks, family dynamics, opportunity for attachment and respite-remembering that attachment is a two way process. A broad based approach is needed, simultaneously addressing remediable elements while promoting resilience, particularly through self-esteem. ${ }^{25}$ Within this, attachment develops, essentially, through "safety" and attunement—safety through routine, explanation and minimising failure, attunement through responding to the feelings behind behaviour rather than the behaviour itself ${ }^{4}$ (table 4). Encouraging understanding of feelings, non-verbal communication, and social cues can begin long before the need becomes apparent through peer relationship problems.

When adoption is deemed necessary, the choice of family must accommodate the implications of the child's preconceptions of relationships. For example, a child insecure about achieving closeness may struggle to compete with one born to the family, focusing feelings onto this child, risking placement breakdown. Sibling relationships reflect parental attachment and need careful assessment. For example, insecure siblings placed together may thrive on each other's failure, with a see-saw effect, risking rejection of one. A home allowing each adequate individual attention is the key.

Strategies adaptive to inadequate parenting, and the effects of fear of, or ambivalence to closeness feel confusing, personally directed and undermining-sometimes to the point of rejection. Understanding the feelings underlying such behaviour allows greater tolerance and empathy, helping the child to learn better ways of relating. Demanding as attention-hungry children may be, their parents generally feel needed, in contrast to the frustrations of parenting those who are emotionally aloof.

Historically, children with attachment problems have often fallen foul of CAMHS service structures and waiting lists in the "wait until he is settled" catch-22. Specialised provision is now increasing. Rapidity of response, separate parental support, flexibility, and continuity seem important. Without a safety net of mutual attachment, difficulty readily leads to crisis and risk of placement breakdown. Adoptive parents frequently feel inadequate and undermined when struggling with the legacy of early neglect-a position which professional involvement can inadvertently reinforce. The tasks required to achieve the priority of attachment need careful definition. "Attachment therapies" are time consuming, in short supply, and largely unevaluated. The extent of need is reflected in a demand for expensive private services.
Established attachment disorder is highly costly for children, families, and society. The focus needs to be on prevention and early intervention. Neurobiological advances now need to be accompanied by clinical research.

\section{FURTHER READING}

Gerhardt S. Why love matters. Hove: Brunner-Routledge, 2004.

\section{ACKNOWLEDGEMENTS}

I would like to thank Alan Emond, Mike Forrester, Karen Illingworth, Raghu Lingam, and Andrew Lister for their helpful comments.

Competing interests: none

\section{REFERENCES}

1 RCPCH. The Charter of the Royal College of Paediatrics and Child Health, paragraph 3[iv] 1996.

2 Bowlby J. Attachment and loss, vol. 1: Attachment. London: Hogarth Press, 1969.

3 Ainsworth MD, Blehar MC, Waters E, et al. Patterns of attachment: a psychological study of the strange situation. Hillsdale, NJ: Lawrence Erlbaum Associates, Inc, 1978.

4 Hughes DA. Psychological interventions for the spectrum of attachment disorders and intrafamilial trauma. Aftachment and Human Development 2003;5:271-7.

5 Allen JP, Hauser ST, Borman-Spurrell E. Attachment theory as a framework for understanding sequelae of severe adolescent psychopathology: an 11 -year follow-up study. J Consult Clin Psychol 1996;64:254-63.

6 Boulet MC, Ethier LS, Couture G. Life events and trauma in chronic negligent mothers. Sante Ment Que 2004;29:221-42.

7 Fahlberg V. A child's journey through placement. London: BAAF, 1994:26-9

8 Stern DN. The first relationship. Cambridge, MA: Harvard University Press, 1977:23-48.

9 Schore AN. Dysregulation of the right brain: a fundamental mechanism of traumatic attachment and the psychopathogenesis of posttraumatic stress disorder. Aust N Z J Psychiatry 2002;36:9-30.

10 Bowlby J. A secure base. London: Tavistock/Routledge, 1988:129-33.

11 Gunnar MR, Morison SJ, Chisholm K, et al. Salivary cortisol levels in children adopted from Romanian orphanages. Dev Psychopathol 2001;13:611-28.

12 Heim C, Owens MJ, Plotsky PM, et al. Persistent changes in corticotropinreleasing factor systems due to early life stress: relationship to the pathophysiology of major depression and post-traumatic stress disorder. Psychopharmacol Bull 1997; 33:185-92.

13 Nemeroff CB. Neurobiological consequences of childhood trauma. J Clin Psychiatry 2004;65(suppl 1):18-28.

14 van Bokhoven I, Van Goozen SH, van Engeland H, et al. Salivary cortisol and aggression in a population-based longitudinal study of adolescent males. J Neural Transm 2004 (published Online First 7 Dec 2004; DOI: 10.1007/ s00702-004-0253-5).

15 Shoal GD, Giancola PR, Kirillova GP. Salivary cortisol, personality, and aggressive behavior in adolescent boys: a 5-year longitudinal study. J Am Acad Child Adolesc Psychiatry 2003;42:1 101-7.

16 Bailey MT, Coe CL. Maternal separation disrupts the integrity of the intestinal microflora in infant rhesus monkeys. Dev Psychobiol 1999;35:146-55.

17 Lubach GR, Coe CL, Ershler WB. Effects of early rearing environment on immune responses of infant rhesus monkeys. Brain Behav Immun 1995;9:31-46

18 Burgess KB, Marshall PJ, Rubin KH, et al. Infant attachment and temperament as predictors of subsequent externalizing problems and cardiac physiology. $J$ Child Psychol Psychiatry 2003;44:819-31.

19 Luecken LJ. Childhood attachment and loss experiences affect adult cardiovascular and cortisol function. Psychosom Med 1998;60:765-72.

20 Quinton D, Rushton A, Dance C, et al. Joining new families: adoption and fostering in middle childhood. Chichester: Wiley, 1998:212-13.

21 Howe D. Parent-reported problems in 211 adopted children: some risk and protective factors. J Child Psychol Psychiatry 1997;38:401-11.

22 O'Connor TG, Marvin RS, Rutter M, et al. Child-parent attachment following early institutional deprivation. Dev Psychopathol 2003;15:19-38.

23 Perry BD. Childhood experience and the expression of genetic potential: what childhood neglect tells us about nature and nurture. Brain and Mind 2002:3:79-100.

24 Dozier M, Stovall KC, Albus KE, et al. Attachment for infants in foster care: the role of caregiver state of mind. Child Dev 2001;72:1467-77.

25 Fonagy $\mathbf{P}$, Steele $\mathrm{M}$, Steele $\mathrm{H}$, et al. The Emanuel Miller Memorial Lecture 1992. The theory and practice of resilience. J Child Psychol Psychiatry 1994;35:231-57. 